1 Title: Effects of male age and female presence on male associations in a large, polygynous

2 mammal in southern India

3

4 Authors: P. Keerthipriya, S. Nandini ${ }^{\dagger}$, T.N.C. Vidya*

5

6 Author affiliation (for all authors): Evolutionary and Organismal Biology Unit,

7 Jawaharlal Nehru Centre for Advanced Scientific Research (JNCASR), Bengaluru 560064,

8 India.

$9 \quad$ Present address: Azim Premji Foundation, Doddakannelli, Sarjapur Road, Bengaluru.

10 Email: P. Keerthipriya: keerthipriya@jncasr.ac.in; S. Nandini:

11 nandini.shetty@azimpremjifoundation.org; T.N.C. Vidya: tncvidya@jncasr.ac.in; ORCID

12 iD for T.N.C. Vidya: 0000-0002-7143-9008.

13

14

$15 *$ Corresponding author.

16

17 Address for correspondence:

18 T.N.C. Vidya

19 Jawaharlal Nehru Centre for Advanced Scientific Research

20 Jakkur

21 Bengaluru - 560 064, India.

22 Email: tncvidya@jncasr.ac.in

23 Phone: +91-80-22082968

24 Fax: +91-80-22082766 


\section{Abstract $(<=\mathbf{2 5 0}$ words $)$}

\section{8}

We present a detailed study of male associations in a roving species, the Asian elephant, using six years of data on identified, nonmusth males. Adult males spent greater proportions of their time solitarily than in mixed-sex or in all-male groups. Old (over 30 years) males were sighted more frequently with their age-peers and less frequently with young (15-30 years) males than expected at random in all-male groups. Young males were not sighted more frequently with old males than with young males, and did not disproportionately initiate associations with old males. These results suggest that male associations, in the absence of females, primarily allow for old nonmusth males to test strengths against agepeers. Social learning from older individuals did not seem to be important in male associations, unlike that observed in African savannah elephants. We also found a constraint on the sizes of all-male groups, similar to that seen in female groups in our study population, and with male group sizes being smaller than that of African savannah elephants. However, most males had a significant top associate in female absence. In mixedsex groups, male associations occurred at random, suggesting that males were tracking female groups independently. Thus, we find some differences in male social organisation compared to the phylogenetically related African savannah elephant that occupies a similar niche, and suggest that ecological factors might have shaped the differences in these male societies.

\section{Keywords}

Asian elephant, male associations, association networks, Kabini Elephant Project, testingstrengths hypothesis, social learning hypothesis, female presence/absence, male age. 
Introduction

55 Adult males and females of many large mammals exhibit sexual dimorphism and strikingly

56 different lifestyles, with female philopatry and male dispersal (see Greenwood 1980,

57 Ruckstuhl and Neuhaus 2000). Following dispersal from their natal groups, males may

58 spend some time alone or in all-male groups, and then form a) relatively stable bonds with

59 female groups (for example, Hrdy 1977 in Hanuman langurs, Packer and Pusey 1987 in

60 lions, Alberts and Altmann 1995 in baboons), b) form mixed-species groups during the

61 breeding season and all-male groups outside of the breeding season (for example, Clutton-

62 Brock et al. 1987 in red deer, Villaret and Bon 1995 in Alpine ibex, Mooring et al. 2003 in

63 desert bighorn sheep), or c) rove between different female groups and form only temporary

64 associations with female groups throughout the year (for example, Best 1979 in sperm

65 whales, Poole 1982 in African savannah elephants, Desai and Johnsingh 1995 in Asian

66 elephants, Baird and Whitehead 2000 in killer whales). The interactions between males

67 themselves in polygynous species with these different kinds of lifestyles are expected to be

68 competitive rather than affiliative, with males competing with one another for access to

69 receptive females (van Hooff and van Schaik 1994). Therefore, strong associations are not

70 expected between males in species with female-philopatry and may occur primarily in the

71 context of coalitions to defend or to contest access to females (for example, Saayman 1971

72 in baboons, Connor et al. 1992, Gerber et al. 2020 in bottlenose dolphins, van Hooff and

73 van Schaik 1994 in non-human primates, Wagner et al. 2008 in hyaenas). However, male-

74 male interactions in all-male groups may be less competitive or aggressive than those within

75 mixed-sex groups (Pusey and Packer 1987 in primates, Robbins 1996 in mountain gorillas).

76 All-male groups may provide an opportunity to test strength against and assess competitors

77 in a more relaxed setting (Bon et al. 1993 in mouflon sheep, Chiyo et al. 2011 in African

78 savannah elephants). Male associations in all-male groups may also be motivated by the 
opportunities available for social learning from older, more experienced males (Evans and

80 Harris 2008, Chiyo et al. 2011, 2012 in African savannah elephants, Bercovitch and Berry 2014 in giraffes). Increased efficiency in obtaining food resources (river otters, Blundell et al. 2002) and improved defense against predators (sperm whales, Curé et al. 2013) are also possible benefits from associating with other males, despite possible intrasexual competition. There has been little study on male association patterns in mammals overall, especially on those species that rove between female groups and do not form stable multimale-multifemale groups or large multimale groups in the non-breeding season. We, therefore, wanted to examine the extent and nature of male associations in such a roving species that is large, polygynous, and faces potentially high male-male competition and potential group size restriction, but is also phylogenetically related to a species with complex male association patterns.

92 Asian elephants (Elephas maximus) are polygynous, with males and females exhibiting 93 different morphologies and adult lifestyles. Female society in this species is organised into 94 clans that show fission-fusion dynamics (de Silva et al. 2011, Nandini et al. 2017, 2018), while pubertal males disperse from their natal groups and only temporarily associate with other males and with female groups thereafter (McKay 1973, Desai and Johnsingh 1995).

97 There are often no clearly defined bull areas. Males are not known to form coalitions to 98 defend females. Males can breed throughout the year, but females are sexually receptive 99 only for a few days (Eisenberg et al. 1971) every four to five years, making receptive 100 females a rare resource, for which males are expected to compete intensely. Male-male 101 dominance interactions have been observed, indicating contest competition (McKay 1973, 102 Daniel et al. 1987, Chelliah and Sukumar 2013, Keerthipriya 2018). 
104 Male Asian and African elephants are thought to be more reproductively active during

105 musth (a rut-like state); however, nonmusth males also acquire some mating and 106 reproductive success (Hollister-Smith et al. 2007, Rasmussen et al. 2007, Chelliah and

107 Sukumar 2015, Kabini Elephant Project, unpublished data). Therefore, competition for

108 females may also exist among nonmusth males, and male-male affiliative associations are

109 expected to be weak. However, males in the African savannah elephant have been shown to

110 have complex relationships, with males preferring to associate with age-peers (Chiyo et al.

111 2011, Goldenberg et al. 2014 - in the case of sexually inactive males) and related males

112 (Chiyo et al. 2011), and there is some evidence for older males being preferred associates or

113 being more central to male society than young males (Evans and Harris 2008, Chiyo et al.

114 2011, Murphy et al. 2020). Male associations were also shown to facilitate social learning:

115 bulls who had an older crop raider as a top associate were more likely to raid themselves

116 (Chiyo et al. 2012). Thus, temporary all-male groups seem to provide an opportunity to spar

117 and test strengths, and also possibly for younger males to learn from knowledgeable, older

118 males in African savannah elephants.

120 Although Asian and African elephants were previously assumed to have similar societies,

121 we now know that there are some differences between the female Asian elephant and

122 African savannah elephant societies (de Silva and Wittemyer 2012, Nandini et al. 2018),

123 probably because of a constraint on female group sizes due to ecology in the Asian elephant

124 (Nandini et al. 2017, 2018). Since males, being larger and continuing to grow in size as they

125 age (Sukumar et al. 1988), are likely to require more food than females, such a constraint

126 might also exist in male Asian elephants and lead to differences in male societies across

127 species, despite their phylogenetic closeness. Moreover, male African savannah elephants

128 were known to return to the same bull areas (areas frequented by males and not by many

129 female groups) when sexually inactive (Poole 1982), providing an opportunity for repeated 
130 associations with specific individuals (although the selection of a bull area may also

131 possibly be a decision to associate with other males in the area; see Lee et al. 2011). An

132 absence of separate bull areas in Asian elephant populations might reduce the frequency of

133 males meeting each other, and hinder the formation of strong male associations. We,

134 therefore, wanted to examine associations among adult male Asian elephants to find out

135 whether possible ecological differences correlated with a different male social structure than

136 in the African savannah elephant, despite the phylogenetic similarity between species.

138 We analysed associations of nonmusth adult males in this paper because musth males spend 139 only a small proportion of their time in all-male groups (Keerthipriya et al. 2020). We

140 aimed to examine the prevalence, strength, and stability of associations among nonmusth

141 Asian elephant males and the factors (male age, presence of female groups, restriction on 142 group size) that might affect male associations. We hypothesized that male (adult, 143 nonmusth, male Asian elephants in this paper, unless specified otherwise) associations 144 might be based on opportunities available for a) social learning from older individuals $145 \mathrm{and} /$ or b) testing strengths. Increased efficiency in obtaining food resources was not likely to 146 be a factor leading to adult male groupings in elephants because individuals require large 147 amounts of food and grouping is expected to create food competition. Defense against 148 predators was also not likely to be important because adult male elephants do not have any 149 natural predators and our work was carried out in Protected Areas. We did not examine 150 genetic relatedness as a cause for associations.

152 We set out to address the following specific questions:

153 1) What are the proportions of time that nonmusth males spend in all-male groups and 154 mixed-sex groups and how are they related to male age? While examining male 155 associations regardless of the males' musth status, we had found that age did not affect 
156 the time spent in mixed-sex or all-male groups (Keerthipriya et al. 2018). We had also

157 found that old males increased their association with females when they entered musth,

158 while young males decreased their association with females when they were in musth,

159 compared to their nonmusth associations (Keerthipriya et al. 2020). Therefore, we

160 expected that nonmusth older males would spend less time with female groups than

161 nonmusth younger males. Although older males were seen more often than younger

162 males in all-male groups of the African savannah elephant (see Chiyo et al. 2011,

163 Goldenberg et al. 2014), that pattern might be reversed among nonmusth males in

164 Kabini if there was a constraint on group size.

2) How does male age and the presence or absence of females in the vicinity affect patterns

167 of associations between nonmusth males? We expected male age to affect associations

168 differently depending on whether males associated primarily for social learning or for

169 testing strength. We expected males to use their time in all-male groups, rather than in

170 mixed-sex groups, to test strength. However, social learning from older males could

171 occur in female absence (learning related to resources) and/or female presence (learning

172 related to reproduction). If male associations were primarily based on social learning

173 from older individuals, younger males would seek out older males more often than

174 expected by chance alone. If male associations were primarily driven by opportunities

175 for social learning, but older males were restricted in the amount of time they spent with

176 other males (possibly due to group size constraints), older males might not spend more

177 time in all-male groups, but the proportion of sightings of young males in which young

178 males associated with older males would be higher than the proportion of sightings of

179 young males in which young males associated with other young males. Older males

180 would also be better connected in male networks if they were preferred as associates by

181 young and old males, although better connectedness of old males could also be observed 
182 if old males had stronger age-peer associations than younger males. If the primary

183 purpose of male associations was to test strengths, males would be expected to associate

184 (relative to population age-structure) to a greater extent with age-peers than with much

185 younger or older individuals, whose relative strengths are easily assessed by size

186 differences. We did not have a priori expectations about whether old or young males

187 would be more likely to associate amongst themselves if there were preferential

188 associations with age-peers. It was possible that young males might show greater

189 preferential association with age-peers than old males since old males might better know

190 their strengths (through experience) than young males. However, it was also possible

191 that old males might show greater preferential association with age-peers because, being

192 more competitive breeders than young males, resolving dominance relationships might

193 be more crucial for them.

195 Since competition for females could play a major role in how males associated, we 196 examined male associations in the immediate presence and absence of females. Unlike 197 the case of the African savannah elephants, no clear indicators of active and inactive 198 sexual states outside of musth have been recognised in Asian elephants. We expected 199 the average number of other males that males met to be lower, and associations to be 200 weaker, in the presence of females than in their absence. It should be noted that if males 201 spent a greater amount of time in the absence of females than in their presence, males 202 would likely also meet other males more frequently in female absence, resulting in the 203 male association network in female absence being denser and better connected than that 204 in female presence. However, this difference should not be significant after controlling 205 for the difference in the number of sightings, if the greater number of associations was 206 merely an effect of the greater amount of time spent. Due to the expected competition 207 among males, we also predicted smaller experienced group sizes of the males in female 
208 presence than absence. It was also possible that males approached female groups by

209 tracking them independent of other males, in which case, we expected males to associate

210 with each other at random. In such a case, we had no $a$ priori expectation about whether

211 the group sizes of males would be higher in female presence or in female absence.

213 3) Is there a restriction on male group size? If there was a constraint on the group sizes of

214 all-male groups, we expected a trade-off between the number of associates of a male and

215 how often the focal male was sighted with those associates. We also expected older

216 males to spend less time in all-male groups or to form smaller all-male groups than

217 younger males because of greater food competition (due to larger body size). However,

218 a similar pattern could also be observed if young males had stronger age-peer

219 associations than old males. On the other hand, if there were stronger age-peer

220 associations among old than young males, we would expect old males to spend more

221 time in all-male groups or to form larger all-male groups than young males, although

222 group-size restriction might reduce the difference.

224 4) Are there preferential associations between nonmusth males and, if so, are they stable

225 over time? We did not have any a priori expectation about whether preferred, stable

226 associations should be present or not, but, if they occurred, we expected them to be less

227 frequent than that in the African savannah elephant due to possible group size $228 \quad$ constraints.

\section{$231 \quad$ Methods}


234 The field study was carried out in Nagarahole and Bandipur National Parks and Tiger

235 Reserves (Nagarahole: $11.85304^{\circ}-12.26089^{\circ}$ N, 76.00075-76.27996 ${ }^{\circ}$ E, $644 \mathrm{~km}^{2}$;

236 Bandipur: $11.59234^{\circ}-11.94884^{\circ} \mathrm{N}, 76.20850^{\circ}-76.86904^{\circ} \mathrm{E}, 872 \mathrm{~km}^{2}$ ) in southern India

237 from March 2009 to July 2014. Nagarahole and Bandipur National Parks are separated by

238 the Kabini reservoir, and we refer to the elephants in the two parks as the Kabini population.

239 Because of the high density of elephants around the reservoir and better visibility for

240 behavioural observations, our sampling was centred around the reservoir, and extended to

241 the forests in either direction with lower frequency of sampling (see Nandini et al. 2017).

242 We sampled pre-selected forest routes (see Nandini et al. 2017 for details) in the study area

243 from early morning to late evening ( 6:30 AM am to 6:00-6:45 PM depending on field

244 permits and light conditions). There were no distinct bull areas in our study area. The adult

245 sex ratio in the study area was 1 male : 4-5 females (Gupta et al. 2016).

247 We tried to sex, age, and identify all the elephants sighted. Asian elephants are sexually 248 dimorphic, with males being taller and bulkier than females apart from differences in 249 genitalia. Females do not possess tusks, although some males (called makhnas) are also 250 tuskless. We estimated age based on shoulder height, body length, skull size, and skin folds 251 (see Vidya et al. 2014), with semi-captive elephants in the same area serving as a reference 252 for ageing older animals. We placed males into the following age categories, based on their 253 estimated ages: calves ( $<1$ year), juveniles $(1-<5$ years), sub-adults $(5-<15$ years), young 254 adults (15-<30 years), and old adults (>=30 years). Young adult males were likely to have 255 completely dispersed from their natal herds but were possibly less reproductively 256 competitive than old adult males, based on studies of African savannah elephants (Poole 257 1982, Poole et al. 2011). The ages used for classifying males into these categories were 258 those calculated at the mid-point of the study period (November 2012). We identified 259 individuals based on a combination of ear, back, tail, tusk, and body characteristics (detailed 
260 in Vidya et al. 2014). We recorded group size, GPS location, time of sighting, and whether

261 adult males were in the presence or absence of females. Females were classified as adults

262 when they were 10 years old (see Nandini et al. 2018). Adult males were said to associate

263 with a female group (one or more adult females and their young that were in close proximity

264 and showed coordinated movement; see Nandini et al. 2018) if they fed within $10 \mathrm{~m}$ (easy

265 physical reach) of a group member or interacted with any group member. When two males

266 associated with the same female group at the same time, they were said to be associating

267 with each other in female presence. Rarely (only three different sightings), males were seen

268 to associate with subadult females (5-10 years old) in the absence of an adult female and

269 this was also considered to be association in female presence. Males were said to associate

270 with each other in female absence if they fed within about $50 \mathrm{~m}$ of each other and there

271 were no females in the vicinity. At this distance, the males would be able to display or react

272 to visual signals, apart from sensing one another through sound or smell. Males could

273 indulge in sparring during their associations, but if males, upon encountering each other,

274 displayed only aggressive interactions and moved away, they were not considered to be 275 associating.

\section{Data Analysis}

278 Data analysis was carried out using only those sightings in which all adult males were aged

279 and identified and female group compositions (if applicable) were known. Of the 878 days

280 of field work between 2009 and 2014, elephants were sighted on 853 days, identified adult

281 males were sighted on 718 days, and nonmusth adult males on 681 days. In many of the

282 analyses mentioned below, only males who were sighted at least 10 times in that particular

283 category (such as group composition type or female presence) while not in musth were used,

284 as associations of males seen rarely are unlikely to represent their actual association patterns

285 and may bias the results. Similarly, if there was a comparison between different categories 
286 (such as associations in female presence and absence), common males sighted at least 10

287 times (when not in musth) in each of the categories were used, unless otherwise mentioned.

288 ANOVAs, GLMs/GLMEs (General Linear Models/Generalised Linear Mixed-Effects

289 Models), and non-parametric tests were performed using Statistica 7 (StatSoft, Inc. 2004)

290 and randomisations (as randomisations of observational data can account for potential

291 sampling bias in social network analyses; see Farine 2017) were carried out using

292 MATLAB (MATLAB R2011a, MathWorks, Inc, 1984-2011, www.mathworks.com) unless

293 specified otherwise.

294

295

Proportions of time spent in all-male and mixed-sex groups and their relationship with male

296 age

297 We calculated the number of minutes individual males (that were seen on at least 5 different

298 days when not in musth) were seen in the following group types and calculated the

299 proportions of each individual's time spent in such groups: 1) solitary, 2) all-male groups

300 with only one adult male (but including subadult or juvenile males and, therefore, not

301 solitary), 3) all-male groups with more than one adult male, and 4) mixed-sex groups. Since

302 the four proportions add up to one and are, therefore, not independent, and the number of

303 males seen in group type 2 was small, we compared only two of the four categories - all-

304 male groups with more than one adult male and mixed-sex groups. Males were categorized

305 into old and young adults as explained in the Field data collection section above. We

306 carried out Wilcoxon's matched-pairs tests, separately on old and young males, to test

307 whether the proportions of time spent in the different group types differed significantly.

308 Since the proportions were calculated for each male, each male was represented only once

309 in this analysis, effectively making male identity random. In order to find out whether old

310 males spent a smaller proportion of their time in mixed-sex groups than young males did,

311 we used a Mann-Whitney $U$ test. 
313 Changes in male associations and time to sighting independence

314 Using data from the last two years of observation (2013-2014), we examined continuous

315 observations of individual males and recorded the number of changes in that male's

316 associations in five-minute bins (all observations that lasted less than five minutes were

317 removed for this calculation). If there were changes in the identities of the adult males in the

318 focal male's group or if the focal male's association changed from female presence to

319 absence (or vice versa), they were counted as changes in the focal male's associations. The

320 time interval at which there was roughly equal probability of a male's association changing

321 or not would indicate the time interval at which sightings could be recorded as independent

322 of each other (in order to avoid pseudoreplication of data). We found this time interval to be

323 about 80 minutes (see Supplementary Material 1). Therefore, for all subsequent analyses of

324 sighting data, we only included independent sightings based on this time interval.

326 Effect of male age and the presence or absence of females on male association patterns

$327 \quad$ Male age and social learning

328 We examined the initiation of associations and the pattern of associations between males to

329 find out whether social learning might be a reason for associating. As mentioned in the

330 Introduction, if associations were primarily based on social learning, younger males would

331 be expected to seek out older males more often than expected by random chance. We,

332 therefore, examined all the instances in which two males (dyadic combinations in the small

333 number of cases where there were more than two males) of different ages were in close

334 proximity and one approached the other and associated with it. It was possible under such

335 circumstances for either of the males to approach the other. We randomly chose one of the

336 males as the focal male and used a generalized linear mixed-effects model (GLME) with a

337 binomial dependent variable ( 0 if the focal male approached the associate and 1 if the focal 
338 male was approached by the associate), age difference (age of the focal male minus the age

339 of the associate) as a continuous predictor variable, and dyad identity as a random factor. If

340 younger males approached older males more often than expected, a significant positive

341 effect of the age difference on the dependent variable would be found. We used the fitglme

342 function in MATLAB R2011a, with a logit link function and Laplace estimation method,

343 and the model was fit using maximum likelihood. For this analysis, we used data only from

344 the years 2011-2014, during which detailed behavioural observations were available, and

345 did not include dyads that were already present when we began the observation. We only

346 used instances (of all males) when observers were present during the beginning of the

347 association and one of the males clearly moved towards the other.

349 We had expected that if social learning was the primary reason for the formation of all-male 350 groups, but older males were restricted in the amount of time they spent with other males, 351 the proportion of young males' time (sightings) that was spent with older males would still

352 be higher than the proportion of young males' sightings spent with other young males. 353 Therefore, we compared these proportions, in female presence and absence, using

354 Wilcoxon's matched-pairs tests. (Young males would spend a greater proportion of their 355 sightings with other young males than with old males if the testing-strength hypothesis was 356 correct.)

358 We had also expected older males to be better connected in male networks if they were 359 preferred as associates by both young and old males (or disproportionately by old males).

360 We examined this by analysing social networks of males. We first calculated the association 361 index (AI; Ginsberg and Young 1992) between pairs of identified males as the number of 362 times (independent sightings) two males were sighted together $\left(N_{\mathrm{AB}}\right)$ divided by the total 363 number of (independent) sightings of the two males. AI between each pair of males was 
364 calculated separately in female presence and female absence (for instance,

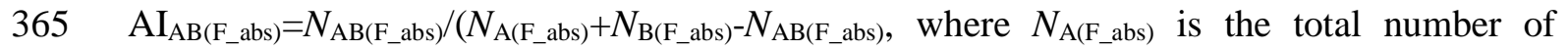
366 sightings of $\mathrm{A}$ in female absence and $N_{\mathrm{B}\left(\mathrm{F}_{-} \mathrm{abs}\right)}$ is the total number of sightings of $\mathrm{B}$ in female

367 absence). We used these AIs to calculate association strength (or weighted degree) for each

368 individual male, as the sum of the AI values between a male and all his associates. We

369 calculated the difference in association strength between the two age-classes (mean

370 association strength of old males - mean association strength of young males) in the

371 observed dataset. We then obtained the same value from each of 5000 permuted datasets

372 (see the section below for details of permutations) and compared the difference in the

373 observed dataset with those from the permuted datasets (see section below; $P<0.025$ for

374 statistical significance as we had no prior expectation about whether the observed values

375 would be lower or higher than the permuted values).

$377 \quad$ Male age and testing strengths

378 In order to find out whether males preferentially associated with age-peers (as predicted by 379 the testing-strengths hypothesis) more often than expected by chance, we used a 380 permutation procedure following Whitehead (2008, pg. 124). This procedure was carried 381 out on the datasets of males in female absence. We generated 5000 males permuted datasets, 382 by flipping (switching) adult males across independent sightings, while keeping the group 383 size and the number of sightings for each male constant, in each permuted dataset. The 384 number of flips performed in each permutation was five times the number of sightings in 385 that dataset. We calculated the number of times old ( $>=30$ years) and young (15-30 years) 386 males were sighted with other males of the same or different age class in the observed 387 dataset and compared these observed values with the values from the permuted datasets. We 388 used the distribution of values from the permuted datasets to determine whether the 389 observed value was greater or lower than that expected by chance $(P=$ proportion of 
390 permuted values that were higher - if the observed value was higher than more than half of

391 the permuted values - or lower - if the observed value was lower than more than half of the

392 permuted values - than the observed value; $P<0.025$ for statistical significance).

393

394 We also compared the proportion of their sightings that old males spent associating with

395 other old males with the proportion of their sightings that they spent associating with young

396 males using Wilcoxon's matched-pairs tests. A higher proportion of sightings with other old

397 males than young males would be seen if the testing-strengths hypothesis was correct.

398

399

Male associations in the presence and absence of females

400 We performed a similar permutation procedure as described in the section above on the

401 female presence dataset, comparing the observed numbers of sightings in which males

402 associated with their age-peers and the other age-class. If association between males was

403 influenced by competition for females, we expected old males to associate less frequently

404 than that expected by random chance. We had also expected the male association network to

405 be denser and better connected in female absence than in female presence because of

406 potential competition between males in the presence of females. We, therefore, compared

407 the following network statistics between male association networks in female presence and

408 absence: mean degree (number of associates of a focal male), mean clustering coefficient

409 (the proportion of the total possible connections between a male's associates that exist),

410 mean path length (the smallest number of connections between two individuals in the

411 network), and network density (the proportion of all possible connections that exist in the

412 network) (Latapy 2008; see Wasserman and Faust 1994). We compared these network

413 statistics and mean AIs between female presence and absence using a sampled

414 randomization test (Sokal and Rohlf 1981, pp. 791-794). We created 5000 permuted

415 datasets (permuted by randomly assigning sightings to female presence or absence, while 
416 conserving the sample sizes for both the categories and ensuring that at least ten sightings of

417 each male were assigned to each category in each permutation). We then compared the

418 observed differences in network statistics and AI between the original female presence and

419 female absence datasets with the differences in statistics between the permuted 'female

420 presence' and 'female absence' datasets. The probability of a significant difference between

421 the observed values was calculated as the proportion of permutations in which the difference

422 in statistic between the permuted datasets was greater than or equal to the difference in

423 statistic between the observed datasets. Since the total numbers of sightings in female

424 presence and female absence were conserved, a significant difference in this test would

425 indicate a difference in network statistic that could not be attributed to the difference in the

426 numbers of sightings.

428 We compared the degree distributions of association networks in female presence and

429 absence with their Poisson expectations (expected for a Erdös-Rényi random network;

430 Erdös and Rényi 1960) to test whether males were associating with each other at random.

432 We examined the effect of female presence on male group size by performing a GLM on

433 experienced group sizes (experienced by individual adult males; counted as the number of

434 adult males in each sighting of the focal male, including the focal male). We used female

435 presence/absence as a fixed factor and male identity as a random factor.

437 Restriction on all-male group size

438 If there was a constraint on group size in all-male groups, a negative relationship would be

439 seen between the number of associates of a male and how frequently the focal male was

440 sighted with those associates. We, therefore, calculated the average of the proportions of 441 sightings of a focal male (out of all the sightings of that male, including solitary sightings) 
442 that the male spent with his different associates. This average proportion of the focal male's

443 sightings spent with his associates was correlated with the number of associates of that male

444 (in female absence) using a Spearman's rank-order correlation. We also examined whether

445 old males spent less time than young males in all-male groups by using the data on

446 proportions of time spent in different types of groups (section towards the beginning of the

447 Methods) and performing a Mann-Whitney $U$ test. We also examined the relationship

448 between the mean experienced group size of a male and his age using Spearman's rank-

449 order correlation.

450

Preferred male associations and stability of associations

452 We tested for preferred associations or avoidance amongst identified males across sampling 453 periods smaller than the entire dataset using SOCPROG 2.6 (Whitehead 2009). We used a 454 sampling period of 14 days and 10,000 permutations with 10,000 flips for each permutation.

455 We used the 'permute associations within samples' method, which tests for long-term 456 (across sampling period) preferences and avoidances (Whitehead 2009). The presence of 457 long-term preference/avoidance is indicated by significantly ( $>95 \%$ of the values of the 458 randomised datasets) higher $\mathrm{SD}$ and $\mathrm{CV}$ of $\mathrm{AI}$ values from the real dataset when compared 459 to the randomised datasets. We used sightings of all males for this analysis.

461 We additionally determined a top associate (based on AI value) for males, separately in 462 female presence and in female absence. Directed networks of males and their top associates 463 were constructed using Gephi 0.8.2 (Bastian et al. 2009). In order to examine whether the 464 identity and strength (AI) of a male's association with his top associate was different from 465 random, we again used the procedure for permuting associations (Whitehead 2008, pg. 124) 466 explained in a section above. We permuted associations between males separately in the 467 female presence and female absence datasets (5000 permutations on each dataset, with the 
468 number of flips in each permutation being five times the number of sightings in that

469 dataset). We compared the AI of a male and his observed top associate with AI values for

470 the same dyad from the permuted dataset, and considered the association to be significant if

471 the observed AI was greater than $95 \%$ of the permuted values. In each permutation, for each

472 male, we also recorded the identity of his permuted top associate. We examined how often

473 the male had the same top associate in the permuted datasets, and considered the identity of

474 his top associate to be significantly different from random if the observed top associate was

475 not the top associate in greater than $95 \%$ of the permuted datasets.

477 In order to find out whether male associations were stable across years, we compared AI

478 matrices between consecutive years, using those males that were common to and sighted at

479 least five times in both years, by performing Mantel tests of matrix correlation (Mantel

480 1967), with 5000 permutations, in MATLAB (MATLAB R2011a, MathWorks, Inc, 1984-

481 2011, www.mathworks.com). Due to limitations of the number of sightings, only data from

482 2011-2014 and only in female absence were used for this analysis.

\section{Results}

487 Proportions of time spent in all-male and mixed-sex groups and their relationship with male

489 We sighted 83 nonmusth males in all (see Supplementary Material 2), of which 44 were 490 seen in the presence of females and 81 in the absence of females. Based on the set of 491 nonmusth males seen on at least five different days $(N=38)$, we found that males spent an 492 average $( \pm \mathrm{SD})$ of $12.3 \%( \pm 11.79 \%)$ of their time in all-male groups and $29.6 \%( \pm 22.73 \%)$ 493 of their time in mixed-sex groups (Figure 1a). Old males spent similar proportions of their 
494 time in all-male and mixed-sex groups (Wilcoxon's matched-pairs test: $T=63.00, Z=0.259$,

$495 N=16, P=0.796$ ), whereas young males spent a significantly higher proportion of their time 496 in mixed-sex groups than in all-male groups (Wilcoxon's matched-pairs test: $T=9.00$, $497 Z=3.815, N=22, P<0.001$, see Figure $1 b$ ). Old males spent a significantly smaller proportion 498 of their time in mixed-sex groups than young males did (Mann-Whitney $U$ test: $U=79.50$, $499 Z_{\text {adj }}=-2.853, P=0.004$, see Figure $\left.1 b\right)$.

500

501 Effect of male age and the presence or absence of females on male association patterns

502 Based on the 80-minute cutoff, there were 2466 independent sightings of adult nonmusth 503 males (374 sightings in female presence and 2092 sightings in female absence) in the study

504 period. Fourteen males ( 4 old and 10 young males) were sighted at least 10 times in female 505 presence, and 32 males (13 old males and 19 young males) were sighted at least 10 times in

506 female absence. Only 12 males were sighted at least 10 times each in the presence and 507 absence of females.

508

$509 \quad$ Male age and social learning

510 The age difference between the focal male and the other male did not significantly affect

511 who approached whom either in female presence (GLME: Estimated coefficient $_{\text {Age }}$ difference $=$ -

$5120.035, t_{\text {stat }}=-0.821, N=19$ approaches, $\left.d f=17, P=0.423\right)$ or in female absence (GLME:

513 Estimated coefficient Age difference $=-0.026, t_{\text {stat }}=-0.772, N=48$ approaches, $\left.d f=46, P=0.444\right)$

514 (Figure 2). Thus, old and young males were equally likely to approach each other to initiate

515 association. We also found no significant difference in the proportion of its sightings that a 516 young male spent with old males (Female presence: mean \pm SD $0.058 \pm 0.035$; Female 517 absence: $0.073 \pm 0.086$ ) and the proportion of its sightings a young male spent with other 518 young males in female presence or absence (Female presence: mean \pm SD: $0.111 \pm 0.090$; 
519 Wilcoxon's matched-pairs test: $T=6.50, Z=1.610, N=10, P=0.107$; Female absence: $0.065 \pm$

$520 \quad 0.045$; Wilcoxon's matched-pairs test: $T=58.00, Z=0.114, N=19, P=0.910)$.

521

522 Examining the effect of male age-class on association strength, we found old males to have 523 only a slightly higher association strength (mean=0.087) than young males (mean=0.052) in

524 the absence of females (difference in mean association strength (old-young): observed 525 dataset: 0.035 ; permuted datasets: mean (2.5 and 97.5 percentiles): $0.003(-0.015,0.020)$,

$526 P<0.001$, Table 1). The observed difference in mean association strengths between the age-

527 classes was not different from the permuted values in female presence (see Table 1).

529 Male age and testing strengths

530 In female absence, old males were sighted together more frequently than expected by 531 chance (permutation test: observed: 42 sightings, males permuted mean (2.5, 97.5 532 percentiles): $25.5(18,34)$ sightings, $P<0.001$; Figure $3 a)$. Old and young males were 533 sighted together less frequently than expected by chance (observed: 51 sightings, permuted: $53469.4(58,80)$ sightings, $P=0.001)$ and young males were sighted together as expected by 535 chance (observed: 38 sightings, permuted: $42.9(33,53)$ sightings, $P=0.178$; Figure $3 a)$. 536 Although these tests were based on small numbers of males, the results remained unchanged 537 when we repeated the analysis using all the identified males (Supplementary Material 3).

539 The proportion of their sightings that old males spent with other old males (mean \pm SD:

$5400.141 \pm 0.116$ ) was higher than the proportion that they spent with young males (mean \pm 541 SD: $0.085 \pm 0.069$; Wilcoxon's matched-pairs test: $T=5.00, Z=2.489, N=13, P=0.013$ ), in 542 female absence.

544 Male associations in the presence and absence of females 
545 We found that old males were sighted together as expected by chance in the presence of

546 females (permutation test: observed: 4 sightings, males permuted mean (2.5 and 97.5

547 percentiles): $1.6(0,4)$ sightings, $P=0.069)$. The numbers of sightings were not different

548 from those expected by chance in the case of old and young males seen together (observed:

54912 sightings, permuted: $11.1(7,16)$ sightings, $P=0.439)$ and young males seen together

550 either (observed: 13 sightings, permuted: $14.7(10,19)$ sightings, $P=0.289)$ (Figure $3 b)$.

551 These results remained unchanged when we repeated the analyses using all identified males

552 without a sighting cutoff (Supplementary Material 3). All three age-class combinations of

553 males were sighted together more often in female absence than in female presence (Figure

5543 3). However, while the observed male association network appeared more connected and

555 denser (higher mean degree, mean clustering coefficient, and density, and lower mean path

556 length) in female absence than in female presence, none of these statistics was significantly

557 different based on sampled randomisation tests (all $P>0.05,12$ males seen at least 10 times

558 each in female presence (249 sightings) and in female absence (855 sightings), Table 2).

559 There was also no significant difference in mean AI between males in the presence and 560 absence of females (Table 2, see Supplementary Material 4 for distributions). Thus, the

561 seemingly more connected network in female absence was probably a result of greater time

562 spent by males in female absence.

563

564 The association network of adult males in female presence was not significantly different

565 from a random network $\left(\chi^{2}=6.122, d f=8, P=0.633\right)$, but the network in female absence was

566 significantly different from random $\left(\chi^{2}=184.647, d f=15, P<0.001\right.$ ) (see Supplementary

567 Material 5).

568

569 Group sizes (number of nonmusth adult males in the sighting) were small in general, with 570 the modal group size of all groups that had an adult male being 1 and the modal group size 
571 of all multi-male groups being 2 (Figure 4a). The experienced group sizes of common males

$572(N=12$, seen 273 times in all in the presence of females and 1304 times in all the absence of

573 females) were larger in female presence (mean \pm SD: $1.6 \pm 0.80$ ) than in female absence

574 (mean \pm SD: $1.2 \pm 0.52 ; F_{1,1553}=48.520, P<0.001$ ). There was a significant main effect of

575 male identity $\left(F_{11,1553}=2.918, P=0.045\right)$ and a significant interaction effect between male

576 identity and female presence $\left(F_{11,1553}=2.157, P=0.014\right.$; Figure $\left.4 \mathrm{~b}\right)$.

\section{Restriction on all-male group size}

579 The mean proportions of sightings that a male spent with an associate was significantly 580 negatively correlated with the number of associates of that male (Spearman's rank-order 581 correlation: $N=31$ males, each with at least one associate and seen at least ten times in

582 female absence, $r_{s}=-0.582, P<0.001$; Figure 5). The relationship was even more negative 583 when the mean proportion of all-male group sightings (rather than all sightings) spent with 584 an associate was correlated with the number of associates of those males $\left(r_{s}=-0.984\right.$, $585 P<0.001$; Figure 5). Thus, in female absence, males that associated with a greater number of 586 males spent a smaller proportion of their sightings on average with each of their associates.

587 However, contrary to expectation, old and young males did not spend significantly different 588 proportions of their time in all-male groups (Mann-Whitney $U$ test: $U=157.50, Z_{\mathrm{adj}}=0.547$, $\left.589 N_{\text {Old }}=16, N_{\text {Young }}=22, P=0.584\right)$, and there was no significant relationship between male age 590 and mean experienced group size (Spearman's rank-order correlation: $N=31$ males, each 591 with at least one associate and seen at least ten times in female absence, $\left.r_{s}=0.213, P>0.05\right)$.

Preferred male associations and stability of associations

594 We found no evidence of preferred male associations across 14-day sampling periods in 595 female presence or in female absence (details in Supplementary Material 6). Only 14.3\% (2 596 out of 14 males; 2 out of 15 dyads as one male had two top associates) of the males had a 
597 significant association with their top associates in female presence, whereas $61.3 \%$ (19 of 31

598 males; one male did not associate with any of the other males) of the males had a significant

599 association with their top associate in female absence (mean significant AI with top

600 associate in female absence $=0.032$, see Supplementary Material 4 for AI distribution;

601 networks shown in Figure 6). We found that the identity of the focal male-top associate

602 dyad was significantly different from random in $13.3 \%$ (2 out of 15 ) of the dyads in female

603 presence and in $83.9 \%$ (26 out of 31 ) of the dyads in female absence.

604

605 Mantel tests showed no significant correlation between association matrices across years, in 606 two out of the three comparisons (Supplementary Material 7).

607

608

609 Discussion

610

611 This is the first detailed study of nonmusth adult male associations in Asian elephants in a

612 relatively undisturbed natural habitat. We found male-male affiliative associations to be 613 weak as expected, and in contrast to that found in the African savannah elephant.

614

615 Proportions of time spent in all-male and mixed-sex groups and their relationship with male 616 age

617 Nonmusth adult males spent only $\sim 12 \%$ of their time in all-male groups in Kabini, in 618 contrast to $\sim 63 \%$ after adjusting for age-effects (Chiyo et al. 2011) and $30.5 \%$ of all bull 619 sightings (Lee et al. 2011) in the Amboseli African savannah elephant population. Unlike 620 Kabini, Amboseli has distinct "bull areas" (Poole 1982) that 'sexually inactive' adult male

621 elephants inhabit but females seldom do, and it is possible that adult males may be more 622 likely to encounter and form strong associations with one another in such bull areas. 
623 However, Chiyo et al. (2011) used observations of all-male groups of males in an area used

624 by both males and females; therefore, the difference cannot be attributed to bull areas in that

625 case. We found evidence for a restriction of all-male group sizes in Kabini (see below), and

626 this restriction may contribute to the smaller time spent in all-male groups. We expected and

627 found old nonmusth males to spend less time with female groups than young nonmusth

628 males. Whereas old males spent a similar proportion of their time in all-male and mixed-sex

629 groups, young males spent more of their time in mixed-sex than all-male groups. As young

630 males invest less in a competitive breeding strategy like musth (see Keerthipriya et al.

631 2020), their greater associations with females might facilitate learning about female groups

632 in areas they have dispersed to and possible opportunistic matings (see Chelliah and

633 Sukumar 2015, Kabini Elephant Project, unpublished data), or reflect a reduced cost of

634 feeding alongside females compared to that faced by old males. Further data are required to

635 examine these possibilities.

637 Effect of male age on association patterns: Reasons for adult male associations

638 As adult Asian elephants do not face any major risks of predation within protected areas and

639 are not known to form coalitions, we had hypothesised that all-male groups could provide

640 an opportunity for younger males to learn from older males or for males to test strengths

641 against age-peers (learning about their relative dominance status, instead of resources). Our

642 results on male associations favour the testing-strengths rather than the social learning

643 hypothesis. Similar-aged males have been shown to preferentially associate with each other

644 and test strengths in all-male groups of other species (Villaret and Bon 1995 - Alpine ibex,

645 Cransac et al. 1998 - mouflon sheep) and all-male groups in the Kabini elephant population

646 may similarly provide a relaxed setting for old nonmusth males to test strengths with age-

647 peers. However, young males in Kabini were sighted together as expected by chance both in

648 female presence and absence. Similar to our results, old (30+ years) males associated more 
649 with age-peers, while the within age-class associations were as expected by chance in 650 younger age-classes in all-male groups in the Amboseli population (Chiyo et al. 2011). As 651 old males regularly enter musth, it may be more important for them than for young males to 652 clarify their relationships when they are not in musth. It would be interesting to find out if 653 dominance relationships formed when not in musth have a bearing on males entering into 654 musth. Old males have also spent more time in their post-dispersal home ranges and might 655 have formed significant associations with familiar age-peers. Male African savannah 656 elephants in Amboseli picked familiar age-peers as sparring partners (Chiyo et al. 2011), 657 and, in other species, interactions with familiar opponents tended to be less aggressive than 658 those with unfamiliar opponents (Smith et al. 1999, López and Martin 2001, Wich and 659 Sterck 2007). It would be interesting to examine the identities of sparring partners amongst 660 males and whether familiarity plays a role in the Kabini population. Murphy et al. (2020) 661 suggested that, perhaps, younger (20-30-year-old African savannah male elephants in their 662 study) males had not yet established a consistent nonmusth home range, leading to lowered 663 stability in association strength compared to older males. However, we found no difference between the turnover rates of young and old nonmusth males (see Supplementary Material 2 ); therefore, this is unlikely to be the reason for the difference observed in our six-year 666 dataset.

668 We did not find any evidence for the social learning hypothesis, which suggests that the 669 superior knowledge of experienced, older males would attract younger males to associate with them in order to learn about the location of food resources in all-male groups or about 671 interactions with females in mixed-sex groups. Contrary to the expectations based on the 672 social learning hypothesis, we found that young males were not sighted with old males to a 673 greater extent than with other young males, either in female presence or absence. During the 674 small amount of time that old and young males spent together, males were equally likely to 
675 approach the other to associate regardless of their relative ages, both in female presence and

676 absence. Therefore, young males did not seek out old males. Although old males had higher

677 association strengths than young males in female absence, this was due to the stronger old

678 male-old male associations, rather than old male-young male associations.

680 In African savannah elephants, older males were found to be important in male networks.

681 Older males spent more time with other males than younger males did (Poole 1982, Chiyo

682 et al. 2011, Lee et al. 2011) and had a greater number of associates in all-male groups

683 (Chiyo et al. 2011) in the Amboseli population. In the Samburu population, sexually

684 inactive older males showed significant affiliation with a higher proportion of available

685 dyads compared to sexually inactive younger males (Goldenberg et al. 2014). Old males had

686 higher centrality in association networks based on all-male groups in Amboseli (Chiyo et al.

687 2011), although when males were classified based on their sexual state (sexually active and

688 inactive) in the Samburu population, there was no correlation between centrality and age in

689 sexually inactive networks and a negative correlation between centrality and age in sexually

690 active networks (Goldenberg et al. 2014). In a recent study in South Africa that examined

691 nonmusth male associations, older males showed higher stability in association strength

692 than younger males across sampling periods; however, age of the male did not affect the

693 stability of the identity of top ranked associates across sampling periods, eigenvector

694 centrality, or association strength of individual males in the network (Murphy et al. 2020).

695 Further, younger males preferentially associated with older males, unlike what we found in

696 Kabini. In Amboseli, males of the 20-29 year age-class associated with older (30+) males

697 more than expected by chance (Chiyo et al. 2011), and male associations seemed to

698 facilitate social learning; males who had an older crop raider as a top associate were more

699 likely to raid themselves (Chiyo et al. 2012). Older African savannah elephant males were

700 also preferred as neighbours while associating by males of all ages, based on observations in 
701 a bull area in Okavango Delta, Botswana (Evans and Harris 2008), and have been

702 considered analogous to the knowledgeable matriarchs of female groups in the species

703 (McComb et al. 2001, Evans and Harris 2008). More generally, preferred association with,

704 and social learning from older, more experienced individuals has been observed in the

705 context of mating behaviour (Pereira 1988, Beecher et al. 1994), and foraging strategies

706 (Rajpurohit et al. 1995, Biro et al. 2003) in other species.

707

708 The greater social role of older males in the African savannah elephant (with younger males

709 preferentially associating with older males) compared to the Asian elephant in female

710 absence may stem from differences in the habitats they occupy. Asian elephants occupy

711 moister, more forested habitats, in which food is possibly more dispersed and unpredictable

712 in space at a very local scale (but possibly more predictable at a larger spatiotemporal scale

713 due to clear seasonality). This local heterogeneity, along with possibly limited food in a

714 feeding patch, and greater predictability at a larger scale might make social learning as

715 adults sub-optimal, as the habitat experienced by individual males might be different (see

716 Boyd and Richardson 1988), and/or superfluous. We also did not find any evidence for

717 social learning in female presence. As young male Asian elephants have been observed to

718 obtain some mating success through opportunistic matings (see Chelliah and Sukumar 2015,

719 Kabini Elephant Project, unpublished data), it is possible that learning in the context of

720 reproductive behaviours occurs at a younger age. It would be interesting to examine whether

721 there is evidence for subadult male Asian elephants socially learning from adults in mixed-

722 sex groups. In our study population, matriarchs of female clans were not the most central

723 individuals (Shetty 2016), which has also been suggested in Uda Walawe in Sri Lanka (de

724 Silva et al. 2011). However, while female group size constraints were found to result in

725 clans being split among small groups (Nandini et al. 2017), which might result in the

726 matriarch not being central to the clan, group size constraint alone may not lead to the 
727 pattern we see amongst males. Although males also associated in small group sizes, young

728 males did not prefer older age-class males as associates more than their age-peers, and

729 young males did not preferentially approach old males when associations did occur.

730 Therefore, it appears that social learning is not the primary reason for adult male

731 associations, even accounting for limitations on group size.

\section{Male associations in the presence and absence of females}

734 We found that the association network of males was non-random in female absence but

735 random in female presence. There were no significant differences in network statistics and

736 AI values between female presence and absence, after accounting for the different number

737 of sightings in the two categories. Thus, the seemingly better connected network in female

738 absence was due to the greater amount of time that males spent in female absence.

739 Contrastingly, in African savannah elephants in Samburu, association networks of sexually

740 inactive males were significantly denser and more clustered than those of sexually active

741 males (Goldenberg et al. 2014). However, sexually active males included musth males and

742 it is not clear to what extent this might contribute to the significant difference between the

743 networks in Samburu.

745 If males were approaching female groups solely due to the presence of females and

746 independent of the presence of other males, we had predicted that male-male associations in

747 female presence would be random, both at an individual and at an age-class level. Our

748 results (network degree distribution being random and all age-classes meeting each other as

749 expected by chance) agree with these predictions. Moss and Poole (1983) observed that

750 males in Amboseli also associated at random when in mixed-sex groups. Males in multi-

751 male mixed-sex groups of other species have also been found to invest in affiliations with

752 females rather than with each other (for example, mountain gorillas, see Sicotte 1994). The 
753 slightly larger male group size in female presence than in female absence could be a result

754 of multiple males tracking the same resource (female groups).

755

756

Restriction on all-male group size

757 We found a negative relationship between how many associates a male had and how much

758 time he spent with them, indicating that all-male groups have a constraint on their group

759 size. Males of both age-classes spent similar proportions of time in all-male groups and

760 experienced similar all-male group sizes, which was expected if there was age-peer

761 association among old but not young males, and a restriction on group size. Female group

762 sizes had also been found to be constrained in the Kabini population (Nandini et al. 2017)

763 and smaller compared to an African savannah elephant population (Nandini et al. 2018).

764 The group size of independent sightings of all-male groups was lower in Kabini than in the

765 Amboseli population of African savannah elephants (mean \pm SD group size of all-male

766 groups with more than one male: Kabini: $2.159 \pm 0.502$, Amboseli: $3.325 \pm 1.995$;

767 Supplementary Material 8, see Chiyo et al. 2011). Low male group sizes have also been

768 observed in other Asian elephant populations. The average group size of adult males

769 (including solitary males) was 1.1 in Mudumalai Wildlife Sanctuary, southern India (Daniel

770 et al. 1987). The maximum all-male group size was 2 in Mudumalai (Daniel et al. 1987), 6

771 in Kabini (although observed in only one sighting), and 5 in Gal Oya in Sri Lanka (McKay

772 1973). In contrast, the maximum group size in Amboseli was 40 (Lee et al. 2011). Lee et al.

773 (2011) classified gregarious males (who spend most of their nonmusth time in all-male

774 groups) as promiscuous (males who spent a lot of time with many associates) or

775 discriminating (males who associated with fewer males for a lot of time). The presence of

776 promiscuous males, along with much larger group sizes, suggest that there is no strong

777 negative relationship between how many associates a male has and how strong his

778 associations are with them in Amboseli. 
780 There are methodological differences between the current study and the one in Amboseli.

781 We considered 50-m as the radius for male association while Chiyo et al. (2011) used a 100-

782 m radius. However, we did not find a large number of instances of males within a 100-m

783 radius but outside a 50-m radius. Chiyo et al. (2011) also included males regardless of

784 musth status/sexual state (which may artificially reduce strength of association; see

785 Goldenberg et al. 2014). However, since musth males in Amboseli associated more with

786 female groups than in all-male groups, and the reverse was true for nonmusth males (Poole

787 1987), it is unlikely that the removal of musth males from the data will lead to a substantial

788 reduction in the all-male group sizes reported in Chiyo et al. (2011).

790 We expected a group size constraint to affect old males to a greater extent than young males

791 due to greater food requirements. However, we found no effect of male age on the time

792 spent in all-male groups. We also found no relationship between male age and the mean

793 experienced group size, but the mean experienced group sizes were close to 1.2, precluding

794 much further reduction in group sizes. Larger Asian elephant male groups are reported

795 elsewhere when they raid crops in risky, but resource-rich environments (see Srinivasaiah et

796 al. 2012), which would relax any constraints on group size. However, anthropogenic threat

797 that could result in larger group sizes is a confounding factor. Intra-group feeding

798 competition has been discussed as a constraint on group sizes in primates (see Chapman et

799 al. 1995), including in all-male groups (Rajpurohit 1995, Steenbeek et al. 2000). Future

800 studies on foraging in male elephants are required to find out the extent to which foraging

801 constraints exist and affect group sizes.

802

803 Preferred male associations and stability of associations 
804 We did not find high correlations between associations across years, in female absence, or

805 evidence for preferred associations among males across two week intervals in either female 806 absence or presence. However, when we examined the males' top associates, we found, in

807 female absence, that the identity of the top associate was different from random for most

808 (84\%) males and a majority of the pairs (61\%) had a higher AI than expected by chance,

809 although the absolute values of these AIs were quite low (Supplementary Material 4). Thus,

810 there were males who showed preference in their choice of top associate but did not or

811 could not spend more time with those associates, and group size restriction may possibly

812 play a role. Such nonrandom top associates were hardly observed in the presence of

813 females. In all-male groups in Amboseli, most of the associations were not significant, with

814 less than $10 \%$ of all the observed $\mathrm{AI}$ values being greater than that $(\mathrm{AI}=0.1)$ predicted under

815 a model of random associations (Chiyo et al. 2011). However, similar to our findings in

816 Kabini, older (>20 years old) adult males in Amboseli also had at least one significant top

817 associate (Lee et al. 2011). Stable and significant affiliation among adult males have been

818 observed in several other species (Packer and Pusey 1982 - lions, Connor et al. 2001 -

819 bottlenose dolphins, Mitani 2009 - chimpanzees, Berghänel et al. 2011 - barbary macaques)

820 but as mentioned in the Introduction, significant relationships among adult males are often

821 thought to be a means to form coalitions to defend females. Adult male coalitions have not

822 been observed in Asian elephants and are unlikely, given the low probability of finding a

823 receptive female and the small sizes of female groups (Nandini et al. 2017). It will be

824 interesting to explore other possible reasons for the significant top male associates we find

825 in Kabini. It is possible that significant affiliations occur between males who are related (see

826 Vidya and Sukumar 2005).

827

828 In summary, we show that associations among nonmusth adult male Asian elephants, 829 although temporary, were affected by male age and the immediate presence of females. We 
830 found associations with age-peers among old males in the absence of females, likely

831 allowing for testing strengths. There was no evidence for social learning driving male

832 associations. There was a constraint on all-male group size, which probably contributed to

833 the small proportion of time males spent in all-male groups. Males associated with each

834 other at random in the presence of females. When we compared our results with those

835 observed in African savannah elephants, we found that Kabini males spent a much smaller

836 proportion of their time in all-male groups of smaller sizes, possibly due to the group size

837 constraints found in Kabini. We also found no evidence for young males preferentially

838 associating with older males in Kabini, unlike the case of African savannah elephants. We

839 posit that the difference in the role of older males is due to the difference in the dispersion

840 of food resources in habitats they occupy, making social learning about resources less

841 valuable in adult male Asian elephants. Overall, while there were some similarities in male

842 associations, ecological differences possibly result in the differences in male social structure

843 between the two species, despite phylogenetic similarity. The relative extents to which the

844 presence/absence of bull areas and differences in feeding competition in non-bull areas

845 explain differences in group size and association time between adult males in the African

846 savannah and Kabini would be interesting to examine. Differences in the nature of male

847 associations between phylogenetically related species have been observed in other taxa:

848 chimpanzees and bonobos show different levels of agonism (Furuichi and Ihobe 1994),

849 macaque populations/species differ in the frequencies of male affiliations depending on

850 group sizes and group sex ratios (Hill 1994). However, while differences between related

851 species in overall social organisation (dolphin species: Parra et al. 2011, Grevy's zebra and

852 onager: Rubenstein et al. 2015) or female social organisation (colobine species: Korstjens et

853 al. 2002, African savannah and Asian elephants: Nandini et al. 2018) that are consistent

854 with resource distributions are known, there is little information on food resource

855 distributions differently affecting male social organisation in related species of large 
856 mammals. Studies on the foraging ecology of male elephants are required in the future to

857 further understand the differences in social organisation between species.

858

\section{Acknowledgments}

860 This work was supported by the Department of Science and Technology's (Government of

861 India) Ramanujan Fellowship (to TNCV) under Grant No. SR/S2/RJN-25/2007 (dated

862 09/06/2008), Council of Scientific and Industrial Research, Government of India, under

863 Grant No. 37(1375)/09/EMR-II and No. 37(1613)/13/EMR-II, National Geographic Society,

864 USA, under Grant \#8719-09 and \#9378-13, and JNCASR. PK was supported as a Ph.D.

865 student by the Council of Scientific and Industrial Research (No. 09/733(0152)/2011-EMR-

866 I). This work is part of PK's Ph.D. thesis. JNCASR also provided logistic support. The

867 funders had no role in study design, data collection and analysis, preparation of the 868 manuscript, or decision to publish.

869

870 We thank the offices of the PCCF, Karnataka Forest Department, and of the Conservators of

871 Forests of Nagarahole and Bandipur National Parks and Tiger Reserves for field permits.

872 We also thank various officials, from various PCCFs and APCCFs, to the Conservators of

873 Forests and Range Forest Officers, to the staff of Nagarahole and Bandipur National Parks

874 for their support across the years. We thank Krishna, Althaf, Ranga, Shankar, Gunda,

875 Rajesh, Binu, and others for field assistance. We thank Deepika Prasad and Arjun Ghosh for

876 help with the initial field data collection. We thank Ajay Desai for useful discussions.

877

878

879 References

880

881 1. Alberts SC, Altmann J. 1995. Balancing costs and opportunities: dispersal in male 
baboons. Am Nat. 145:279-306.

883 2. Baird RW, Whitehead H. 2000. Social organization of mammal-eating killer whales: group stability and dispersal patterns. Can J Zool. 78:2096-2105.

3. Bastian M, Heymann S, Jacomy M. 2009. Gephi: an open source software for exploring and manipulating networks. Proc Third Internat ICWSM Conf. 20098:361-362.

4. Beecher MD, Campbell SE, Stoddard PK. 1994. Correlation of song learning and 888 territory establishment strategies in the Song Sparrow. Proc Natl Acad Sci. 91:1450$889 \quad 1454$.

890 5. Bercovitch FB, Berry PS. 2015. The composition and function of all-male herds of T 891 hornicroft's giraffe, Giraffa camelopardalis thornicrofti, in Zambia. Afr J Ecol. 53:167892174.

893 6. Berghänel A, Ostner J, Schröder U, Schülke O. 2011. Social bonds predict future 894 cooperation in male Barbary macaques, Macaca sylvanus. Anim Behav. 81:1109-1116.

895 7. Best PB. 1979. Social organisation in sperm whales, Physeter macrocephalus. In: Winn 896 HE, Olla BL, editors. Behavior of marine mammals, Volume 3: Cetaceans. New York: Plenum press. p. 227-289.

898 8. Biro D, Inoue-Nakamura N, Tonooka R, Yamakoshi G, Sousa C, Matsuzawa T. 2003. 899 Cultural innovation and transmission of tool use in wild chimpanzees: evidence from 900 field experiments. Anim Cogn. 6:213-223.

901 9. Blundell GM, Ben-David M, Bowyer RT. 2002. Sociality in river otters: cooperative 902 foraging or reproductive strategies? Behav Ecol. 13:134-141.

903 10. Bon R, Dubois M, Maublanc ML. 1993. Does age influence between-rams 904 companionship in mouflon (Ovis gmelini)? Rev Ecol-Terre Vie. 48:57-64.

905 11. Boyd R, Richerson PJ. 1988. An Evolutionary Model of Social Learning: The Effects of 906 Spatial and Temporal Variation. In: Zentall T and Galef BG, editors. Social Learning: 
907 Psychological and Biological Perspectives. Hillsdale, New Jersey: Lawrence Erlbaum $908 \quad$ Associates. p. 29-48.

909 12. Chapman CA, Chapman LJ, Wrangham RW. 1995. Ecological constraints on group 910 size: an analysis of spider monkey and chimpanzee subgroups. Behav Ecol Sociobiol. $911 \quad 36: 59-70$.

912 13. Chelliah K, Sukumar R. 2013. The role of tusks, musth and body size in male-male 913 competition among Asian elephants, Elephas maximus. Anim Behav. 86:1207-1214.

914 14. Chelliah K, Sukumar R. 2015. Interplay of male traits, male mating strategies and 915 female mate choice in the Asian elephant, Elephas maximus. Behaviour. 152:1113-1144. 916 15. Chiyo PI, Archie EA, Hollister-Smith JA, Lee PC, Poole JH, Moss CJ, Alberts SC. 917 2011. Association patterns of African elephants in all-male groups: the role of age and 918 genetic relatedness. Anim Behav. 81:1093-1099.

919 16. Chiyo PI, Moss CJ, Alberts SC. 2012. The influence of life history milestones and 920 association networks on crop-raiding behavior in male African elephants. PLoS $921 \quad$ One. $7: \mathrm{e} 31382$.

922 17. Clutton-Brock TH, Iason GR, Guinness FE. 1987. Sexual segregation and 923 density-related changes in habitat use in male and female Red deer (Cervus elaphus). J 924 Zool. 211:275-289.

925 18. Connor RC, Smolker RA, Richards AF. 1992. Two levels of alliance formation among 926 male bottlenose dolphins (Tursiops sp.). Proc Natl Acad Sci. 89:987-990.

927 19. Connor RC, Heithaus MR, Barre LM. 2001. Complex social structure, alliance stability 928 and mating access in a bottlenose dolphin 'super-alliance.' Proc R Soc Lond B Biol 929 Sci. $268: 263-267$.

930 20. Cransac N, Gerard JF, Maublanc ML, Pépin D. 1998. An example of segregation 931 between age and sex classes only weakly related to habitat use in mouflon sheep (Ovis 932 gmelini). J Zool. 244:371-378. 
933 21. Curé C, Antunes R, Alves AC, Visser F, Kvadsheim PH, Miller PJ. 2013. Responses of

934 male sperm whales (Physeter macrocephalus) to killer whale sounds: implications for 935 anti-predator strategies. Sci Rep. 3:1579.

936 22. Daniel JC, Desai AA, Sivaganesan N, Datye HS, Rameshkumar S, Baskaran N,

937 Balasubramanian M, Swaminathan S. 1987. Ecology of the Asian elephant (Final 938 report). Bombay: Bombay Natural History Society.

939 23. de Silva S, Ranjeewa AD, Kryazhimskiy S. 2011. The dynamics of social networks $940 \quad$ among female Asian elephants. BMC Ecol. 11:17.

941 24. de Silva S, Wittemyer G. 2012. A comparison of social organization in Asian elephants $942 \quad$ and African savannah elephants. Int J Primatol. 33:1125-1141.

943 25. Desai AA, Johnsingh AJT. 1995. Social organization and reproductive strategy of the 944 male Asian elephant (Elephas maximus). In: Daniel JC and Datye H, editors. A week 945 with elephants. Bombay Natural History Society: Oxford University Press. p. 532-532.

946 26. Eisenberg JF, McKay GM, Jainudeen MR. 1971. Reproductive behavior of the Asiatic 947 elephant. Behaviour. 38:193-224.

948 27. Erdös P, Rényi A. 1960. On the evolution of random graphs. Publ Math Inst Hungarian $949 \quad$ Acad Sci. 5:17-61.

950 28. Evans KE, Harris S. 2008. Adolescence in male African elephants, Loxodonta africana, 951 and the importance of sociality. Anim Behav. 76:779-787.

952 29. Farine DR. 2017. A guide to null models for social network analysis. Methods Ecol $953 \quad$ Evol. 8:1309-1320.

954 30. Furuichi T, Ihobe H. 1994. Variation in male relationships in bonobos and chimpanzees. 955 Behaviour. 130:211-228.

956 31. Gerber L, Connor RC, King SL, Allen SJ, Wittwer S, Bizzozzero MR, Friedman WR, 957 Kalberer S, Sherwin WB, Wild S, Willems EP, Krützen M. (2020). Affiliation history 
958

959

960

961

962

963

964

965

966

967

968

969

970

971

972

973

974

975

976

977

978

979

980

981

982

and age similarity predict alliance formation in adult male bottlenose dolphins. Behav Ecol. 31: 361-370.

32. Ginsberg JR, Young TP. 1992. Measuring association between individuals or groups in behavioural studies. Anim Behav. 44:377-379.

33. Goldenberg SZ, de Silva S, Rasmussen HB, Douglas-Hamilton I, Wittemyer G. 2014. Controlling for behavioural state reveals social dynamics among male African elephants, Loxodonta africana. Anim Behav. 95:111-119.

34. Greenwood PJ. 1980. Mating systems, philopatry and dispersal in birds and mammals. Anim Behav. 28:1140-1162.

35. Gupta M, Ravindranath S, Prasad D, Vidya TNC. 2016. Short-term variation in sex ratio estimates of Asian elephants due to space use differences between the sexes. Gajah $44: 5-15$.

36. Hill DA. 1994. Affiliative behaviour between adult males of the genus Macaca. Behaviour. 130:293-308.

37. Hollister-Smith JA, Poole JH, Archie EA, Vance EA, Georgiadis NJ, Moss CJ, Alberts SC. 2007. Age, musth and paternity success in wild male African elephants, Loxodonta africana. Anim Behav. 74:287-296.

38. Hrdy SB. 1977. The langurs of Abu- Female and Male Strategies of Reproduction. Cambridge: Harvard University Press.

39. Keerthipriya P. 2018. Associations, dominance interactions, and musth in male Asian elephants in Nagarahole and Bandipur national parks, southern India. Doctoral dissertation. JNCASR.

40. Keerthipriya P, Nandini S, Gautam H, Revathe T, Vidya TNC. 2020. Musth and its effects on male-male and male-female associations in Asian elephants in NagaraholeBandipur, southern India. J Mammal. 101:259-270. 
983 41. Keerthipriya P, Nandini S, Vidya TNC. 2018. Effects of male age and female presence

984 on male associations in a large, polygynous mammal in southern India. bioRxiv. 985485144.

986 42. Korstjens AH, Sterck EH, Noë R. 2002. How adaptive or phylogenetically inert is 987 primate social behaviour? A test with two sympatric colobines. Behaviour. 139:203-226.

988 43. Latapy M. 2008. Main-memory triangle computations for very large (sparse (power989 law)) graphs. Theor Comput Sci. 407:458-473.

990 44. Lee PC, Poole JH, Njiraini N, Sayialel CN, Moss CJ. 2011. Male social dynamics: 991 Independence and beyond. In: Moss CJ, Croze H, Lee PC, editors. The Amboseli 992 elephants: a long-term perspective on a long-lived mammal. Chicago: University of 993 Chicago Press. p. 224-237.

994 45. López P, Martín J. 2001. Fighting rules and rival recognition reduce costs of aggression 995 in male lizards, Podarcis hispanica. Behav Ecol Sociobiol. 49:111-116.

996 46. Mantel N. 1967. The detection of disease clustering and a generalized regression 997 approach. Cancer Res. 27:209-220.

998 47. McComb K, Moss C, Durant SM, Baker L, Sayialel S. 2001. Matriarchs as repositories 999 of social knowledge in African elephants. Science. 292:491-494.

1000 48. McKay GM. 1973. Behavior and ecology of the Asiatic elephant in southeastern Ceylon. 1001 Smithson Contrib Zool. 125:1-113.

1002 49. Mitani JC. 2009. Male chimpanzees form enduring and equitable social bonds. Anim 1003 Behav. 77:633-640.

1004 50. Mooring MS, Fitzpatrick TA, Benjamin JE, Fraser IC, Nishihira TT, Reisig DD, 1005 Rominger EM. 2003. Sexual segregation in desert bighorn sheep (Ovis canadensis 1006 mexicana). Behaviour. 140:183-207. 
1007 51. Moss, CJ, Poole JH. 1983. Relationships and social structure of African elephants. In:

1008 Hinde RA, editor. Primate social relationships: An integrated approach. London:

1009 Blackwell Scientific Publications. p. 315-325.

1010 52. Murphy D, Mumby HS, Henley MD. 2020. Age differences in the temporal stability of a

1011 male African elephant (Loxodonta africana) social network. Behav Ecol. 31:21-31.

1012 53. Nandini S, Keerthipriya P, Vidya TNC. 2017. Seasonal variation in female Asian

1013 elephant social structure in Nagarahole-Bandipur, southern India. Anim

1014 Behav. 134:135-145.

1015 54. Nandini S, Keerthipriya P, Vidya TNC. 2018. Group size differences may mask

1016 underlying similarities in social structure: a comparison of female elephant

$1017 \quad$ societies. Behav Ecol. 29:145-159.

1018 55. Packer C, Pusey AE. 1982. Cooperation and competition within coalitions of male lions:

1019 kin selection or game theory? Nature. 296:740-742.

1020 56. Packer C, Pusey AE. 1987. The evolution of sex-biased dispersal in lions.

$1021 \quad$ Behaviour. 101:275-310.

1022 57. Parra GJ, Corkeron PJ, Arnold P. 2011. Grouping and fission-fusion dynamics in

1023 Australian snubfin and Indo-Pacific humpback dolphins. Anim Behav. 82:1423-1433.

1024 58. Pereira ME. 1988. Effects of age and sex on intra-group spacing behaviour in juvenile

1025 savannah baboons, Papio cynocephalus cynocephalus. Anim Behav. 36:184-204.

1026 59. Poole JH. 1982. Musth and male-male competition in the African elephant. Doctoral 1027 dissertation. University of Cambridge.

1028 60. Poole JH. 1987. Rutting behavior in African elephants: the phenomenon of musth. $1029 \quad$ Behaviour. 102:283-316.

1030 61. Poole JH, Lee PC, Njiraini N, Moss CJ. 2011. Longevity, competition and musth: a 1031 long-term perspective on male reproductive strategies. In: Moss CJ, Croze H, Lee PC, 
1032 editors. The Amboseli elephants: a long-term perspective on a long-lived mammal.

1033 Chicago: University of Chicago Press. p. 272-290.

1034 62. Pusey AE, Packer C. 1987. Dispersal and Philopatry. In: Smuts BB, Cheney DL,

1035 Seyfarth RM, Wrangham RW, Struhsaker TT, editors. Primate societies. Chicago:

$1036 \quad$ University of Chicago Press. p. 250-266.

1037 63. Rajpurohit LS. 1995. Temporary splitting or subgrouping in male bands of Hanuman 1038 langurs, Presbytis entellus, around Jodhpur, western India. Mammalia. 59:3-8.

1039 64. Rajpurohit LS, Mohnot SM, Sommer V. 1995. Wanderers Between Harems and 1040 Bachelor Bands: Male Hanuman Langurs (Presbytis entellus) At Jodhpur in Rajasthan. $1041 \quad$ Behaviour. 132:255-299.

1042 65. Rasmussen HB, Okello JBA, Wittemyer G, Siegismund HR, Arctander P, Vollrath F, 1043 Douglas-Hamilton I. 2007. Age-and tactic-related paternity success in male African 1044 elephants. Behav Ecol. 19:9-15.

1045 66. Robbins MM. 1996. Male-male Interactions in heterosexual and all-male wild mountain 1046 gorilla groups. Ethology. 102:942-965.

1047 67. Rubenstein DI, Sundaresan SR, Fischhoff IR, Tantipathananandh C, Berger-Wolf TY.

1048 2015. Similar but different: dynamic social network analysis highlights fundamental 1049 differences between the fission-fusion societies of two equid species, the onager and 1050 Grevy's zebra. PLoS One. 10:e0138645.

1051 68. Ruckstuhl KE, Neuhaus P. 2000. Sexual segregation in ungulates: a new 1052 approach. Behaviour. 137:361-377.

1053 69. Saayman GS. 1971. Behaviour of the adult males in a troop of free-ranging chacma 1054 baboons (Papio ursinus). Folia Primatol. 15:36-57.

1055 70. Shetty N. 2016. Social Structure, Genetic Relatedness, and Dominance Relationships in 1056 Female Asian Elephants in Nagarahole and Bandipur National Parks, Southern India. 1057 Doctoral dissertation. JNCASR. 
1058 71. Sicotte P. 1994. Effect of male competition on male-female relationships in bi-male 1059 groups of mountain gorillas. Ethology. 97:47-64.

1060 72. Smith LK, Fantella SL, Pellis SM. 1999. Playful defensive responses in adult male rats

1061 depend on the status of the unfamiliar opponent. Aggress Behav. 25:141-152.

1062 73. Sokal RR, Rohlf FJ. 1981. Biometry (second edition). New York: WH Feeman and 1063 Company.

1064 74. Srinivasaiah NM, Anand VD, Vaidyanathan S, Sinha A. 2012. Usual populations, 1065 unusual individuals: insights into the behavior and management of Asian elephants in 1066 fragmented landscapes. PLoS One. 7:e42571.

1067 75. StatSoft, Inc. 2004. STATISTICA (data analysis software system), version 7.0. StatSoft, 1068 Inc., Tulsa. www.statsoft.com.

1069 76. Steenbeek R, Sterck EHM, deVries H, van Hooff JARAM. 2000. Costs and benefits of 1070 the one-male, age-graded, and all-male phases in wild Thomas's langur groups. In: 1071 Kappeler PM, editor. Primate males. Cambridge: Cambridge University Press. p 130$1072 \quad 145$.

1073 77. Sukumar R, Joshi NV, Krishnamurthy V. 1988. Growth in the Asian elephant. Proc: $1074 \quad$ Anim Sci. 97:561-571.

1075 78. The MathWorks, Inc. 2004. MATLAB 7 (R14). The MathWorks, Inc., Natick. 1076 www.mathworks.com.

1077 79. Van Hooff JA, Van Schaik CP. 1994. Male bonds: afilliative relationships among 1078 nonhuman primate males. Behaviour. 130:309-337.

1079 80. Vidya TNC, Prasad D, Ghosh A. 2014. Individual identification in Asian elephants. $1080 \quad$ Gajah. 40:3-17.

1081 81. Vidya TNC, Sukumar R. 2005. Social organization of the Asian elephant (Elephas 1082 maximus) in southern India inferred from microsatellite DNA. J Ethol. 23:205-210. 
1083 82. Villaret JC, Bon R. 1995. Social and spatial segregation in Alpine ibex (Capra ibex) in

1084 Bargy, French Alps. Ethology. 101:291-300.

1085 83. Wagner AP, Frank LG, Creel S. 2008. Spatial grouping in behaviourally solitary striped 1086 hyaenas, Hyaena hyaena. Anim Behav. 75:1131-1142.

1087 84. Wasserman S, Faust K. 1994. Social Network Analysis: Methods and Applications. 1088 Cambridge and New York: Cambridge University Press.

1089 85. Whitehead H. 2008. Analyzing Animal Societies: Quantitative Methods for Vertebrate 1090 Social Analysis. Chicago: University of Chicago Press.

1091 86. Whitehead H. 2009. SOCPROG programs: analyzing animal social structures. Behav $1092 \quad$ Ecol Sociobiol. 63:765-778.

1093 87. Wich S, Sterck E. 2007. Familiarity and threat of opponents determine variation in 1094 Thomas langur (Presbytis thomasi) male behaviour during between-group encounters. 1095 Behaviour. 144:1583-1598. 


\section{Figure legends}

1100

1101 Figure 1. The proportion of time that a) males (sighted on five days or more) spent in

1102 different group types and b) old and young males (sighted on five days or more) spent in

1103 mixed-sex and adult all-male groups. Pairwise comparisons with significant results are

1104 marked with an asterix, and those with non-significant results are marked as NS (Not

1105 Significant). Error bars are standard deviations.

1106

1107 Figure 2. The proportion of instances when the younger male approached the older male,

1108 and the proportion when the older male approached the younger male, to initiate association,

1109 in female presence and absence. The proportions were not different from one another in

1110 female presence and absence and hence, pairwise comparisons results are marked as NS

1111 (Not Significant).

1112

1113 Figure 3. Permuted and observed numbers of times adult males (sighted 10 times or more in

1114 that category) of the same and different age-classes were sighted together in a) female

1115 absence and b) female presence. Comparisons where the observed value was significantly

1116 different from those of the permuted datasets are marked with an asterix. Old males are

$1117>=30$ years and young males are 15-30 years old. Please note that the $\mathrm{Y}$ axis is on different

1118 scales in the two panels.

1119

1120 Figure 4. a) Proportion of sightings of all groups containing at least one male, of different

1121 group sizes (different numbers of adult males) and b) the experienced group sizes of

1122 common males in female presence and absence. Error bars are 95\% CI.

1123 
1124 Figure 5. The mean proportion of a) sightings (out of the total sightings of the male) and b)

1125 all-male group sightings (out of the total all-male group sightings of the male), that a male

1126 spent with an associate plotted against the number of associates of that male. Results from

1127 Spearman's rank-order correlations are written in the plot.

1128

1129 Figure 6. Networks of males and their top associates in a) female presence and b) female

1130 absence. Nodes representing old males are coloured dark blue and those representing young

1131 males are coloured light blue.

1132

1133 


\section{Tables}

1135

1136 Table 1. Difference in mean association strength between males of the two age-classes in

1137 observed and permuted datasets. The associated probability values ( $P=$ number of

1138 permutations whose difference in mean association strength is higher than that based on the

1139 observed dataset / number of permutations) are provided. Significant comparisons

$1140 \quad(P<0.025)$ are marked in bold.

1141

\begin{tabular}{ccccc}
\hline & $\begin{array}{c}\text { Observed } \\
\text { difference in }\end{array}$ & Difference in mean association & \\
Category & mean association & strength (Old-Young) in & \\
& strength & permuted datasets & $P$ \\
& (Old-Young) & Mean $(2.5$ and 97.5 percentiles $)$ & \\
& & & & 0.027 \\
Female presence & 0.061 & $-0.003(-0.0625,0.0621)$ & \\
Age-class (Old) & & $\mathbf{0 . 0 0 3 ~ ( - 0 . 0 1 4 7 , 0 . 0 1 9 9 )}$ & $<\mathbf{0 . 0 0 1}$ \\
Female absence & & &
\end{tabular}

1142

1143

1144 
1145 Table 2. Network statistics based on observed and permuted male associations in female

1146 presence and female absence. $P=\left(\right.$ number of times difference random $\geq$ difference $\left._{\text {observed }}\right) /$

1147 number of randomisations (5000). None of the comparisons was significant.

1148

\begin{tabular}{|c|c|c|c|c|c|}
\hline \multirow[b]{2}{*}{ Category } & \multirow[b]{2}{*}{ Mean AI } & \multicolumn{3}{|c|}{ Mean clustering Mean path } & \multirow[b]{2}{*}{ Density } \\
\hline & & Mean degree & coefficient & length & \\
\hline $\begin{array}{c}\text { Female presence } \\
\text { observed }\end{array}$ & 0.005 & 2.167 & 0.300 & 2.345 & 0.197 \\
\hline $\begin{array}{c}\text { Female absence } \\
\text { observed }\end{array}$ & 0.003 & 4.500 & 0.577 & 1.697 & 0.409 \\
\hline Female presence & 0.004 & 1.463 & 0.224 & 2.054 & 0.133 \\
\hline permuted mean (SD) & $(0.0011)$ & $(0.4246)$ & $(0.2263)$ & $(0.4013)$ & $(0.0386)$ \\
\hline Female absence & 0.003 & 4.887 & 0.592 & 1.623 & 0.444 \\
\hline permuted mean (SD) & $(0.0002)$ & $(0.3184)$ & $(0.0723)$ & $(0.0621)$ & $(0.0289)$ \\
\hline$P$ value & 0.1126 & 0.9948 & 0.6316 & 0.2784 & 0.9448 \\
\hline
\end{tabular}

1149

1150

1151 


\section{$1152 \quad$ Figures}

1153

1154 Figure 1.

1155

a)

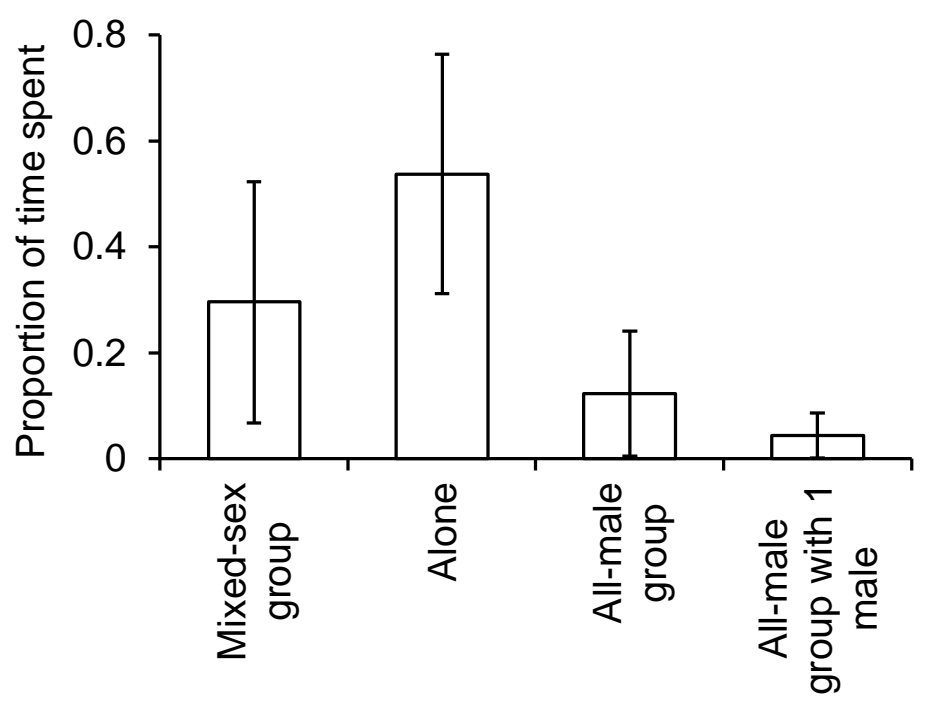

b)

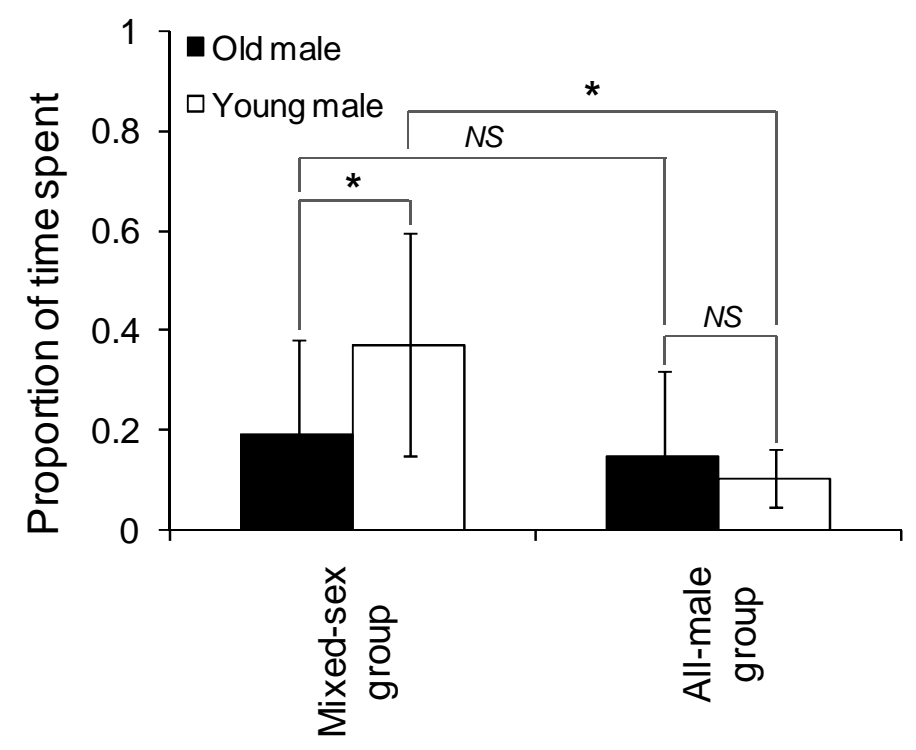

1156 
bioRxiv preprint doi: https://doi.org/10.1101/485144; this version posted June 2, 2020. The copyright holder for this preprint (which was not certified by peer review) is the author/funder. All rights reserved. No reuse allowed without permission.

1159 Figure 2.

1160

1161

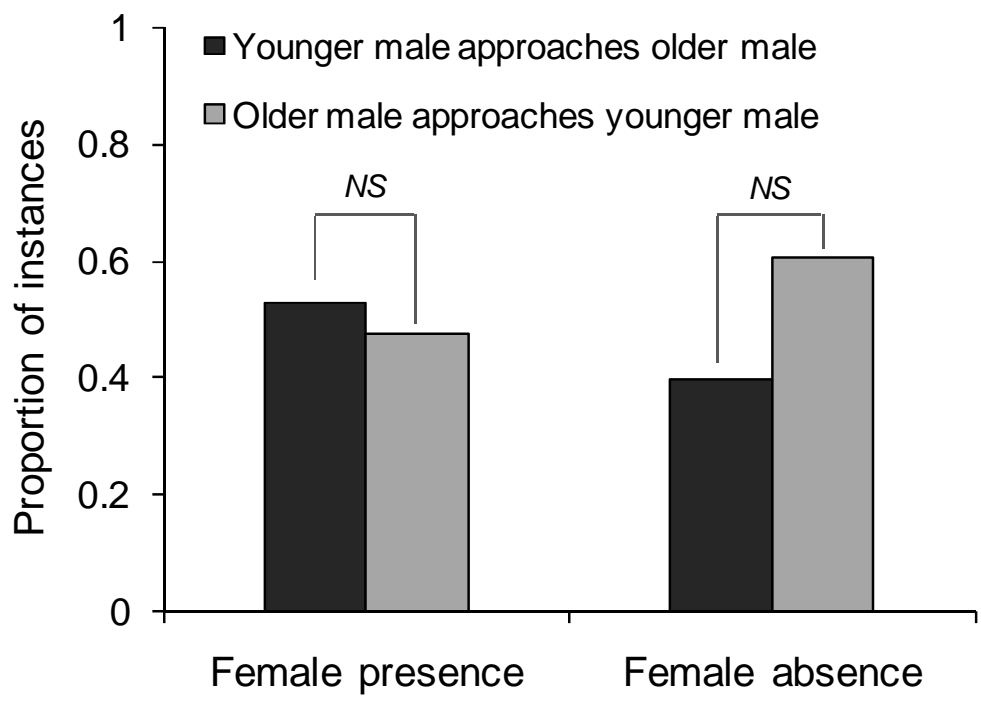

1162

1163

1164 


\section{Figure 3.}

1166

a) Female absence

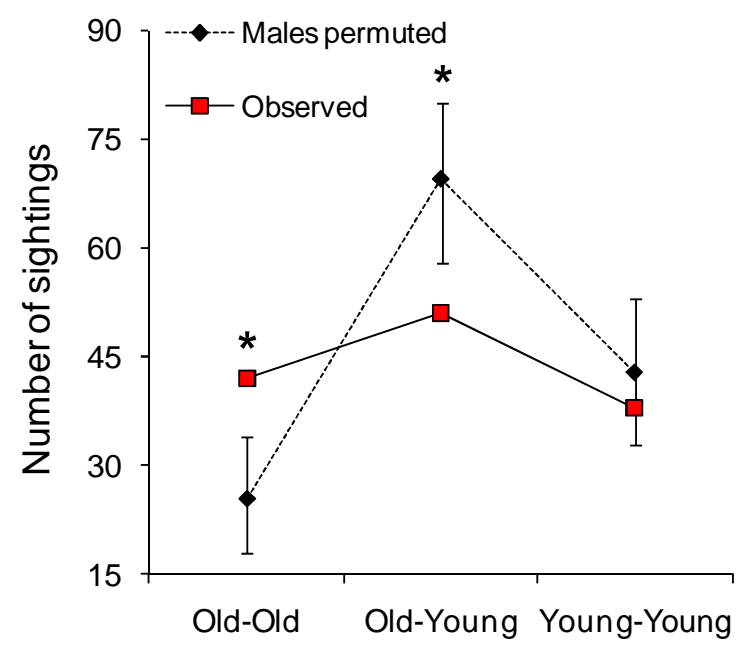

b) Female presence

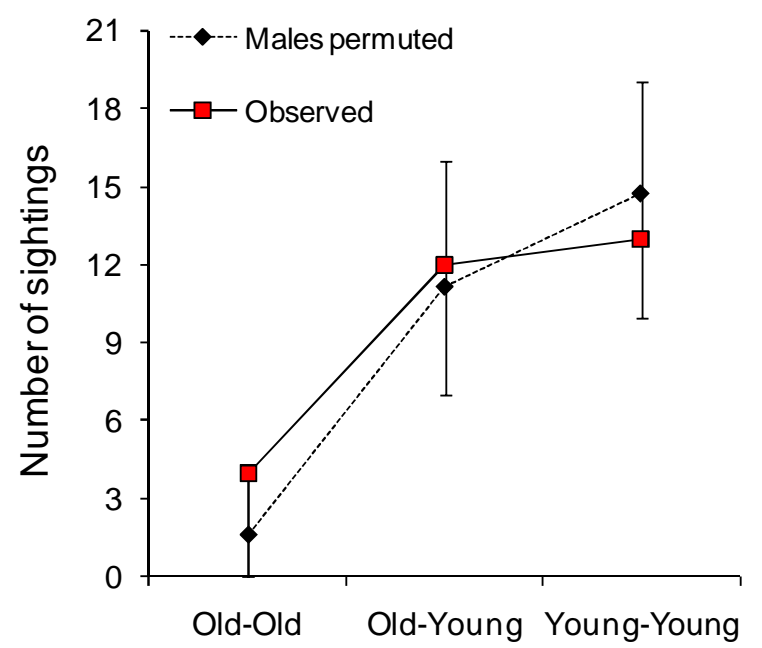

1167

1168

1169 
1170 Figure 4.

1171

a)

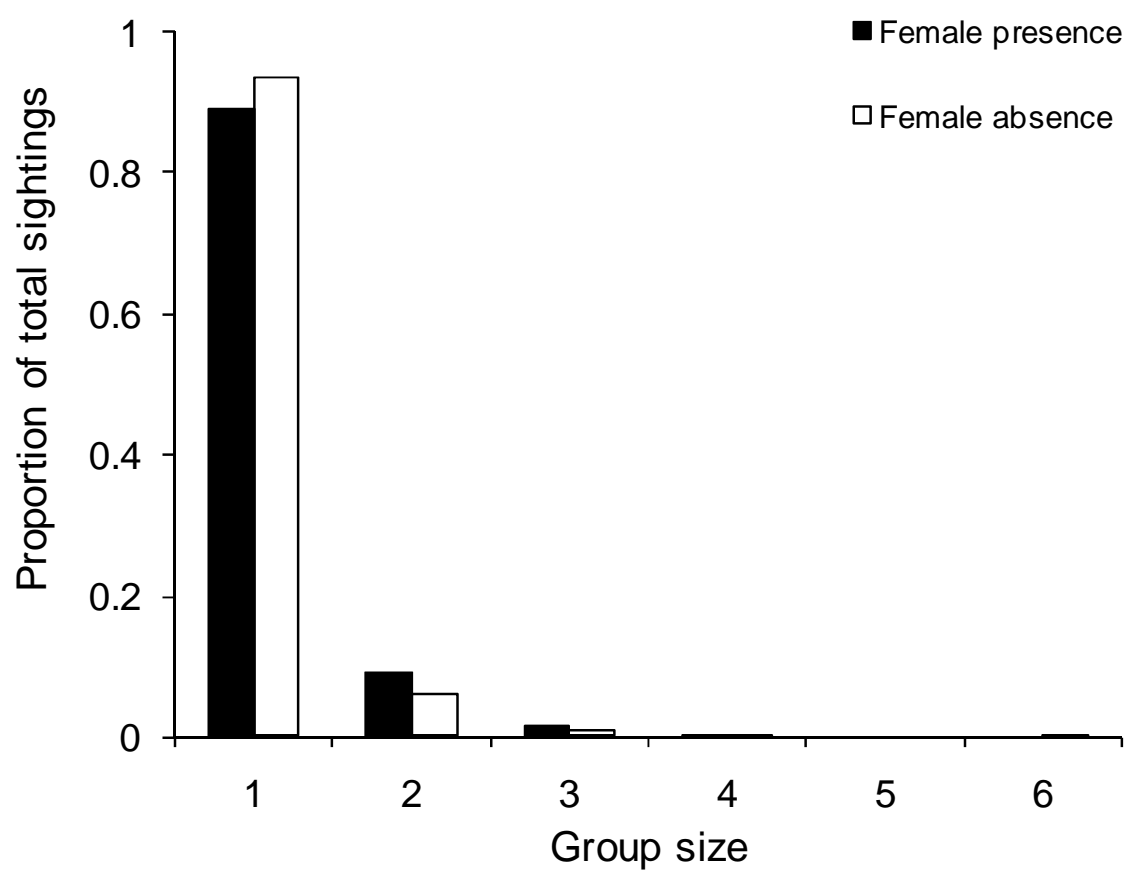

b)

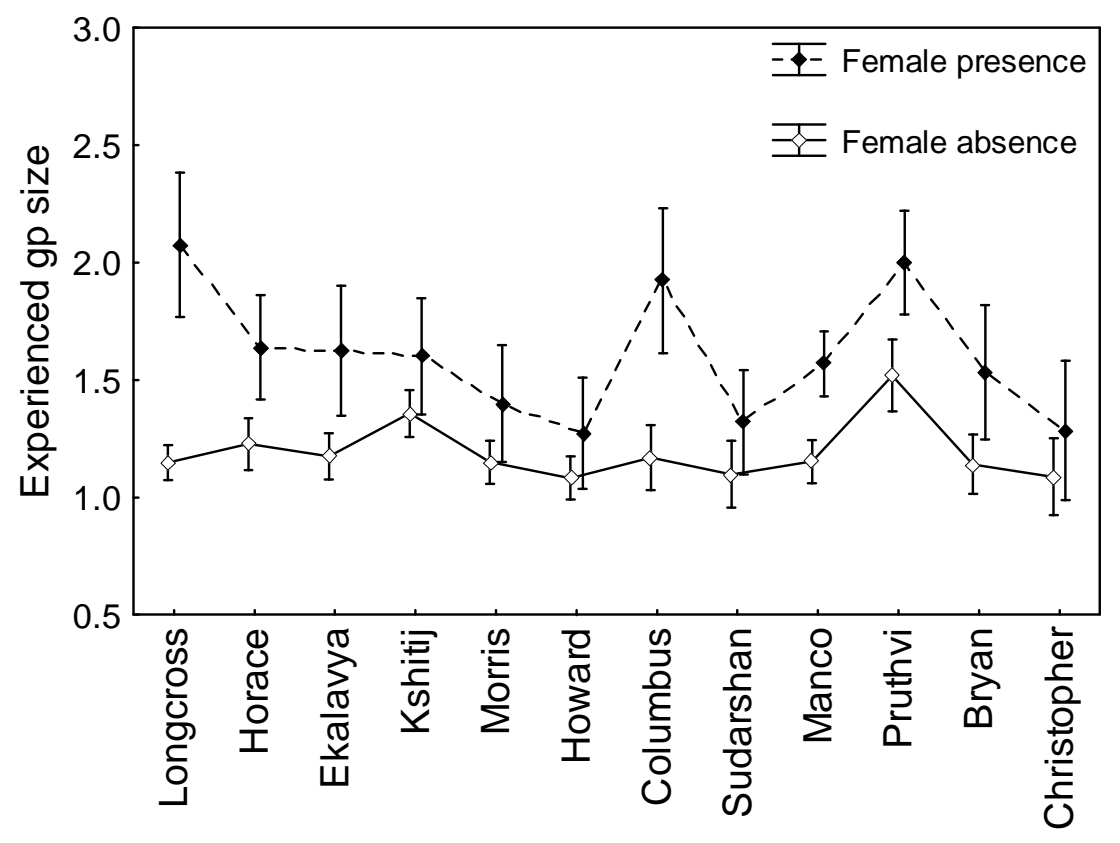


1175 Figure 5.

1176

a)

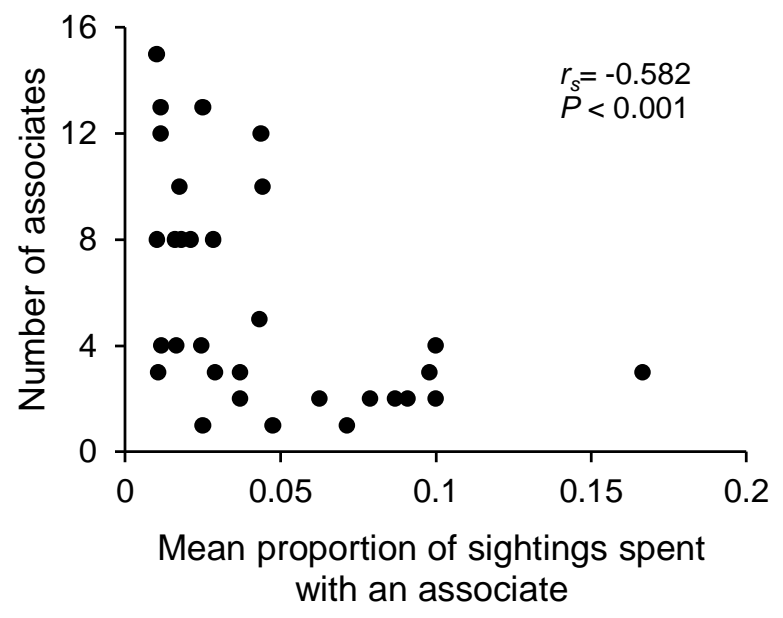

b)

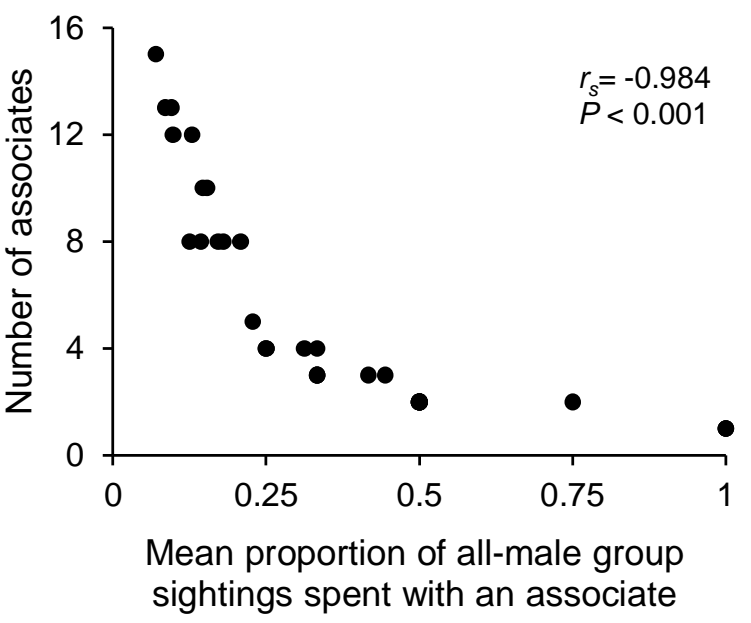

1177

1178

1179

1180 
bioRxiv preprint doi: https://doi.org/10.1101/485144; this version posted June 2, 2020. The copyright holder for this preprint (which was not certified by peer review) is the author/funder. All rights reserved. No reuse allowed without permission.

\section{Figure 6.}

1182

a) Female presence

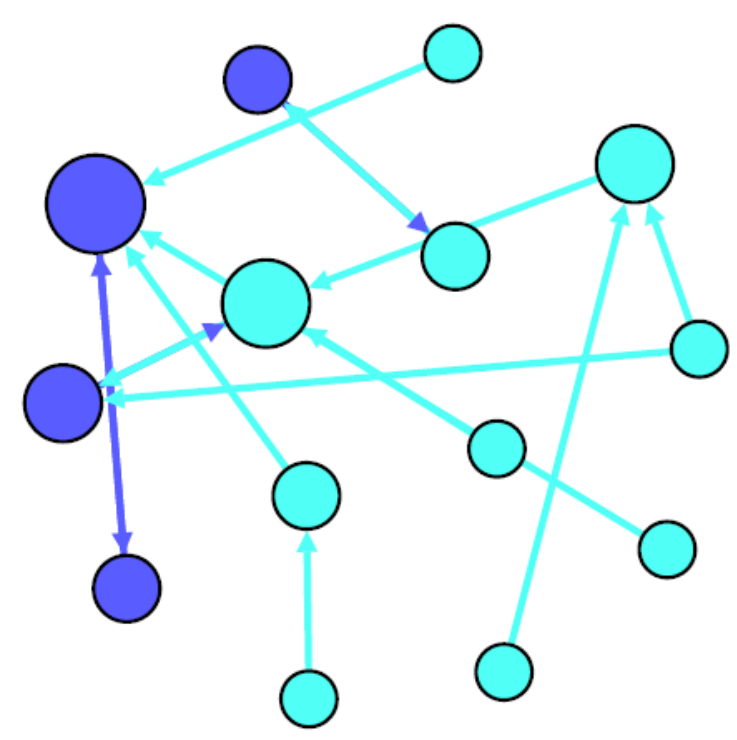

b) Female absence

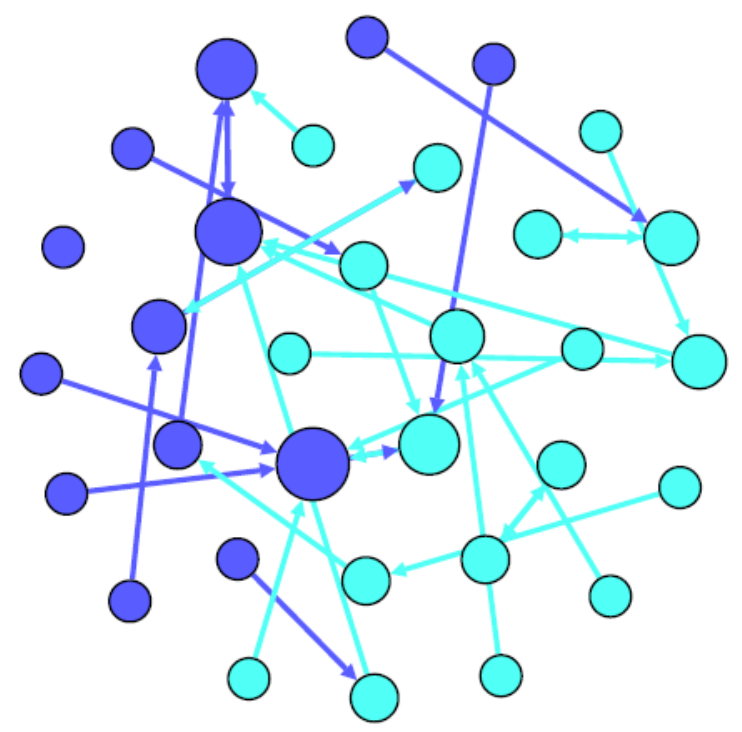

1183

1184 